\title{
Early functional outcome after subvastus or parapatellar approach in knee arthroplasty is comparable
}

\author{
Wouter L.W. van Hemert $\cdot$ Rachel Senden • \\ Bernd Grimm • Matthijs J.A. van der Linde • \\ Arno Lataster • Ide C. Heyligers
}

Received: 16 February 2010/ Accepted: 28 September 2010/Published online: 17 October 2010

(c) The Author(s) 2010. This article is published with open access at Springerlink.com

\begin{abstract}
Purpose In total knee arthroplasty, tissue-sparing techniques are considered more important, as functional gain could become more advantageous when early mobilization is commenced. The parapatellar approach is most often used, whereas the subvastus approach is a suitable alternative. Presently, it is unknown, according to true objective measurements, which of the two is most advantageous.

Methods In this prospective randomized double-blind, short-term trial measurements (KSS, WOMAC, PDI, VAS, ability to perform) were obtained at day 1 , day 3,1 week, 6 weeks, and 3 months.

Results The subvastus group $(n=20)$ showed only significantly less extension lag direct postoperative $(P=0.04)$ compared with the parapatellar group $(n=20)$. Other scores were not significantly different. The Dynaport ${ }^{\circledR}$ knee test, an objective performance-based tool, could not demonstrate significant differences. A blunt anatomical dissection was carried out in both observational and histological to support findings. A dense innervation of the distal vastus medialis was found. This is at risk employing the subvastus approach. Both approaches harm the suprapatellar bursa. The vastus medialis sheath must be detached distally to open the knee joint. No true separate vastus medialis obliquus could be identified.
\end{abstract}

\section{W. L.W.van Hemert $(\bowtie) \cdot$ R. Senden · B. Grimm •}

M. J.A.van der Linde - I. C. Heyligers

Department of Orthopaedic Surgery and Traumatology,

Atrium Medical Centre, PO Box 4446, 6401 CX Heerlen,

The Netherlands

e-mail:wht02@atriummc.nl

\section{A. Lataster}

Department of Anatomy and Embryology,

Maastricht University, Maastricht, The Netherlands
Conclusion Comparable to literature, only mild advantage employing the subvastus approach was found, but only early postoperative and not objectively. As this approach is also not suitable in every case, we will continue to use the parapatellar approach.

Keywords Knee replacement - Subvastus approach . Performance-based test . Vastus medialis anatomy . Clinimetrics

\section{Introduction}

Optimizing rehabilitation after total knee replacement will likely provide better functioning of the knee joint but also avoids complications and reduces healthcare costs [18]. Postoperative recovery of knee function is dependent on patient factors such as body mass index (BMI) and preoperative functioning of the knee and tissue-sparing techniques $[1,3,6,9]$.

Postoperative rehabilitation of knee function is also dependent on the method of assessment employed [8]. Knee flexion appears to be less important than patientrelated outcomes such as WOMAC functioning, since it seems to correlate more with patient satisfaction and pain [22]. Therefore, clinical evaluation after total knee replacement should be measured with multiple items [2]. Assessment must include a pain score and a range of motion. Function should be assessed separately. Ryd et al. [31] claim large bias of subjective knee scores after knee arthroplasty and question the reliability. Therefore, potential under- and over-performance of these scores is likely.

Preservation of integrity of the quadriceps muscle group is essential to knee function of the quadriceps and faster recovery $[6,9,11,23]$. The parapatellar approach is 
commonly used to expose the knee joint. Using the less frequent medial "subvastus" approach, the extensor mechanism is deemed to be preserved, as patella tendon junction remains unharmed.

Weinrauch et al. [40] showed that patients who had undergone knee replacement through a parapatellar approach had a significant larger extension lag than patients in the subvastus group early postoperative. However, a randomized trial by Weinhardt et al. [39] on this topic showed similar results in terms of pain, operation time, and complications. Patients after knee replacement via subvastus approach reached 90 degrees of flexion earlier but were similar at time of discharge.

Matsueda et al. [20] compared a group of total knee arthroplasty (TKA) patients with parapatellar approach and subvastus approach retrospectively at 6 months. There were no significant differences for range of motion, Knee Society Score (KSS), knee function scores, and stairclimbing ability. In the subvastus group, there were significantly fewer knees requiring a lateral retinacular release, concluding that the subvastus approach led to improvement of patellar tracking and stability, but not to increased function.

Therefore, it can be questioned whether functional differences, if any, only occur in earlier phases of recovery. Also, knee scores may not capture existing differences equally [37]. Moreover, the subvastus approach might not result in better tissue sparing, as it may harm viable structures [5, 24].

A study to establish early postoperative differences between the parapatellar and the subvastus approach was conducted, using a performance-based test to complement standard scores. It was hypothesized that a subvastus approach would not lead to a functional faster recovery. Also, an anatomical study was conducted to explore the anteromedial anatomy of the knee to find explanations why the subvastus approach would not possibly result in a better postoperative function $[20,39]$ and to study the anatomical structures at risk employing either of the two techniques [14].

\section{Materials and methods}

In this study, 40 patients with symptomatic unilateral osteoarthritis of the knee and indicated for total knee arthroplasty (TKA) were enrolled in a double-blind prospective randomized design. Patients were divided in a group of 20 patients who underwent a parapatellar approach and another group of 20 patients who were operated on using the subvastus approach, just prior to surgery. Approval was acquired from the local Medical Ethics Committee.
An uncemented Scorpio cruciate retaining total knee system (Stryker, Warsaw, IN, USA) was implanted by either of the two senior authors (ML or IH). As the parapatellar approach is employed as the standard approach, both surgeons performed five subvastus procedures prior to this study to minimize learning-curve bias. The patella was left unresurfaced in all cases but was everted in the parapatellar approach group. Patients with a previous contralateral knee implantation, a poor medical condition, cognitive or language problems to complete the questionnaires, age over 80 years, and those that were unable to perform a gait test were not included.

Posttreatment rehabilitation was similar for both groups and consisted of a joint-care program rehabilitation protocol. Full weight-bearing and active exercises were commenced the first day after surgery as tolerated. Patients were discharged after 5 days standard and rehabilitated throughout the study outpatient, three times a week, by the same team of therapists. Exercises for active muscle strengthening and range of motion were similar for all.

Both patients and the investigators (WH and RS) were blinded to the type of approach. The skin incision was equal in both groups, and access to the OR-report was only allowed after the completion of 3 months of follow-up.

The measurements were performed just prior to surgery and postoperative at 2,6, and 12 weeks. They consisted of Knee Society Score (KSS) [13], where we continuously used it by breaking down in knee and function score, Western Ontario and McMaster Universities Index of Osteoarthritis (WOMAC) (lowest is best) [4], VAS for pain (lowest is best), pain disability index (PDI) (lowest is best [33]), and the Dynaport ${ }^{\circledR}$ knee test [36] (also performed on day 3). The existence of an active extension deficit but passively correctable extension (extension lag) and the ability to mobilize was checked at day 1 . VAS was recorded at day 1 and day 3 as well.

The preoperative stage of osteoarthritis was classified according to the Ahlback's scoring system. Implant position was verified on a 6-week postoperative standing AP and lateral radiograph and standing long leg radiograph (failure if more than 5 degrees deviation).

The DynaPort ${ }^{\circledR}$ knee test is a short (30 min) standardized test to assess the quality of movement or patients with a knee dysfunction. It objectively assesses functional abilities in a standardized set of tasks closely related to ADL (activities of daily living). Test persons wear several belts around their trunk and legs, while performing 29 sets of tasks related to ADL, such as walking several distances, climbing different stair heights, and picking an lifting objects and always in the same order. The rationale of the DynaPort ${ }^{\circledR}$ system has been explained by van den Dikkenberg et al. [36], and validity has been proven [26, 27]. Accelerometers generate the DynaPort ${ }^{\circledR}$ knee test subscores 
(locomotion, rise and descend, lift and move, and transfers) and the overall score. An item too difficult can be skipped, but results in 0 points.

\section{Anatomical study}

Two lower limb specimens (left and right) were harvested from two different formalin-injected human cadavers. Both specimens were amputated $20 \mathrm{~cm}$ distally from the tibial tuberosity, and proximal structures were spared. The blunt dissection technique was carried out as described previously by van Mameren et al. [38].

The cutis and subcutis were completely removed by sharp dissection. To explore the subcutaneous course of the greater saphenous vein and the infrapatellar and main branch of the saphenous nerve, a blunt dissection was utilized (Fig. 1). A small circular band of cutis and subcutis was left intact at the proximal and distal end of this specimen, and the (para)patellar blood supply and the infrapatellar nerve supply were investigated by dissecting layers of deep fascia ("fascia lata/cruris") around the patella sharply and fatty "gliding" tissue between these layers bluntly (Fig. 1).

In both knees, the sartorius, vastus medialis, rectus femoris, and vastus lateralis compartments were opened in that order by longitudinal incisions of the deep fascia lying over it (Fig. 1). Paraffin-embedded hematoxylin and eosinstained histological sections were produced to identify these neurovascular structures. The dissection procedure was photographed using a digital SLR camera (Canon 400D, Canon Inc.) mounted on a tripod with a standard 50 -mm lens $\mathrm{f} 1.8$ in macro mode.
Statistical analysis

Data analysis was performed using SPSS 12.0 (Chicago, Illinois, USA). Reported values are mean \pm standard deviation (SD). This study design involves patients who are considered equal both prior to the study and after 1 year of follow-up [20, 39]. Previous papers report differences between 10 and 20 that are reported in Dynaport-employed scores [35-37]. We considered one standard deviation of difference clinically relevant. Based on this, an a priori power analysis ( $\alpha$ error probability of 0.05 and a power of 0.8 ) produced a minimum sample size of 34 patients.

The between-subject differences of mean at each time point were analyzed using a Student's $t$ test or a MannWhitney test depending on the data distribution. The within-subject differences of mean were analyzed in a oneway repeated measures ANOVA model with the approach as a between-subjects factor. Post-hoc comparisons were checked using a paired-samples $t$ test. For proper use of repeated measures analysis of variance (ANOVA), the number of observations should be larger than $n+10$, where $n$ is the number of level of repeated measures. This study was comprised of four scenarios, and there were 24 patients in the smallest group. If the sample size is between 16 and 40, a $t$-distribution can be applied if the sampling distribution is moderately skewed, unimodal, without outliers. Therefore, the validity and applicability of the used test were considered acceptable [21].

We used the Ahlback's scoring system in a cross table and used a chi-square test to exclude differences preoperative. The difference in mean of early postoperative extension lag, the ability to mobilize the first day
Fig. 1 Dissection of superficial neurovascular structures with ' $\mathrm{x}$ ' opened vastus medialis compartment and '*'distal aponeurotic vastus medialis plate

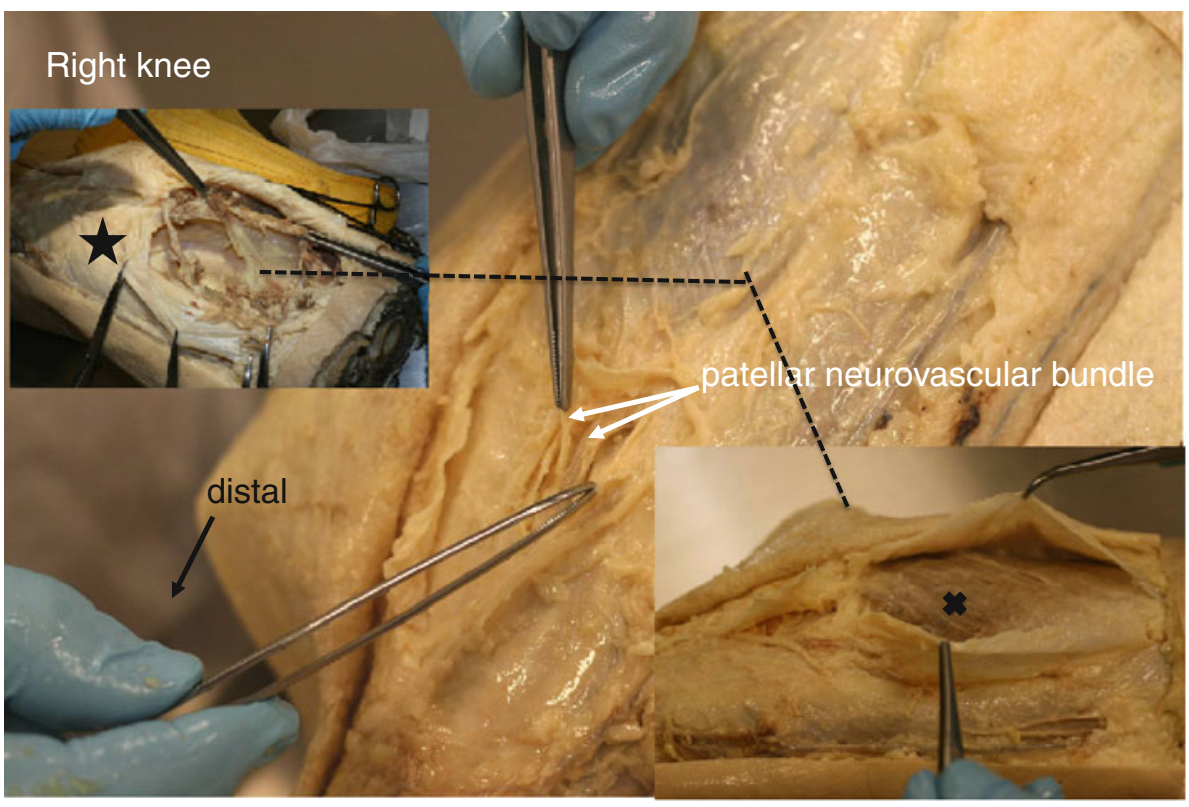


Table 1 Demographic characteristics

\begin{tabular}{llll}
\hline & $\begin{array}{l}\text { Parapatellar } \\
\text { group }(n=20)\end{array}$ & $\begin{array}{l}\text { Subvastus } \\
\text { group }(n=20)\end{array}$ & n.s. \\
\hline Age & $70.9( \pm 7.1)$ & $70.3( \pm 11.8)$ & n.s. \\
BMI & $30.3( \pm 5.9)$ & $29.2( \pm 5.5)$ & \\
Sex & $13 \mathrm{~F} / 7 \mathrm{M}$ & $14 \mathrm{~F} / 6 \mathrm{M}$ & \\
Stage of osteoarthritis (Ahlback) & $1(n=10)$ & $1(n=11)$ & \\
& $2(n=6)$ & $2(n=5)$ & \\
Surgical time & $3(n=4)$ & $3(n=4)$ & n.s. \\
Blood loss (24-h drain production) & $69( \pm 12.6)$ & $74.7( \pm 18.6)$ & n.s. \\
\hline
\end{tabular}

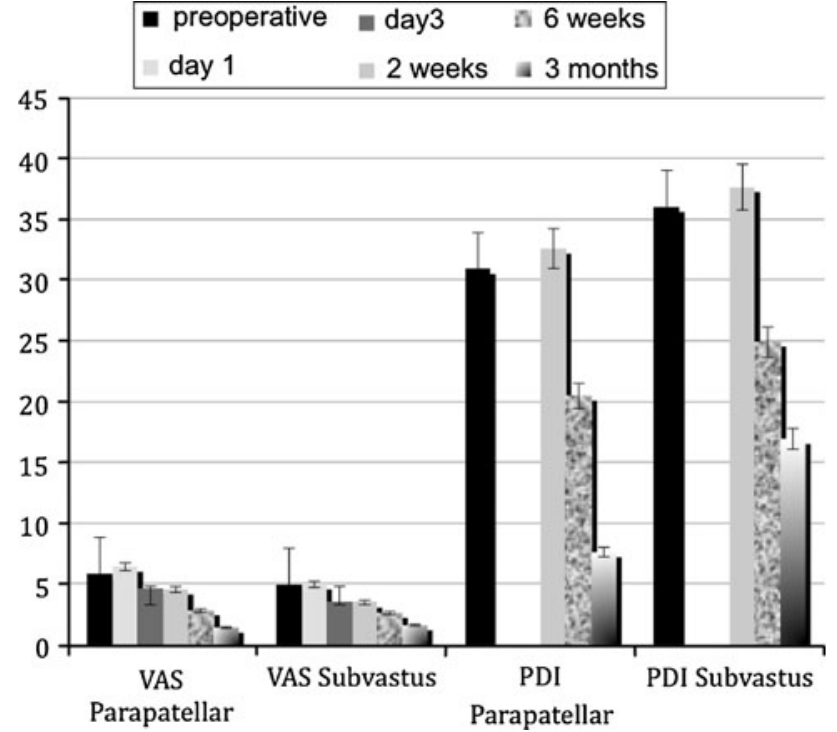

Fig. 2 Mean $( \pm$ SD) Vas and PDI score in time

postoperative, to participate in the third day test and the 3 -month implant position including existing patellar tilt on the patella sunrise view were analyzed as a proportion sample using Fisher's Exact test. Level of significance was set at $P<0.05$.

\section{Results}

All patients were available throughout the entire testing period. Preoperative demographic characteristics are presented in Table 1. The mean peri-operative blood loss was recorded using the 24-h drain production, as surgery was performed with a tourniquet.

The VAS, which only showed a significant difference at the third day, and PDI scores are shown in Fig. 2.

At the third day, nine patients in the parapatellar group showed an extension lag compared with three in the subvastus group $(P=0.04)$. Knee flexion is displayed in Fig. 3 and showed no significant differences.

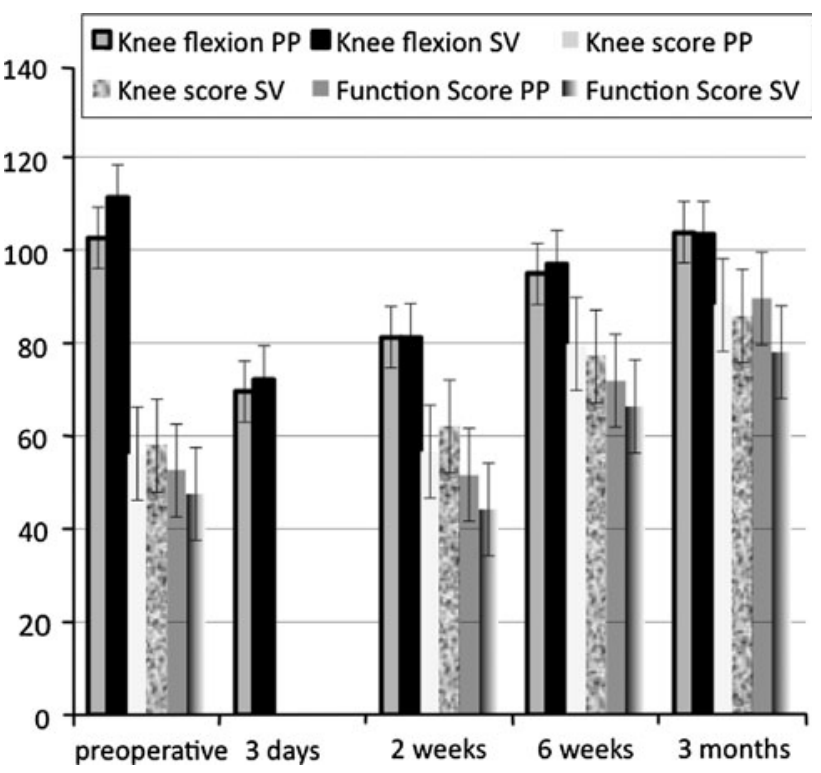

Fig. 3 Mean $( \pm \mathrm{SD})$ knee flexion, knee score, and function score in time $P P$ parapatellar, $S V$ subvastus

At 2, 6, and 12 weeks postoperative, there were no significant differences between groups as indicated by Dynaport ${ }^{\circledR}$ knee test and its subscores (Fig. 4), as well as KSS (Fig. 3), WOMAC pain, function and stiffness (Fig. 5).

The improvements within subject, determined using repeated measures model, were below significant levels. No post-hoc tests were obtained here.

Implant position was considered normal in all cases, and patellar tilt was not found to be significantly different between groups (n.s.).

One patient in the subvastus group sustained a deep infection, which resulted in extensive debriding surgery.

\section{Anatomical dissection}

In both anatomical specimens, the fibers of the vastus medialis muscle were removed by bluntly detaching them from the dense connective tissue (Fig. 6). A large number 


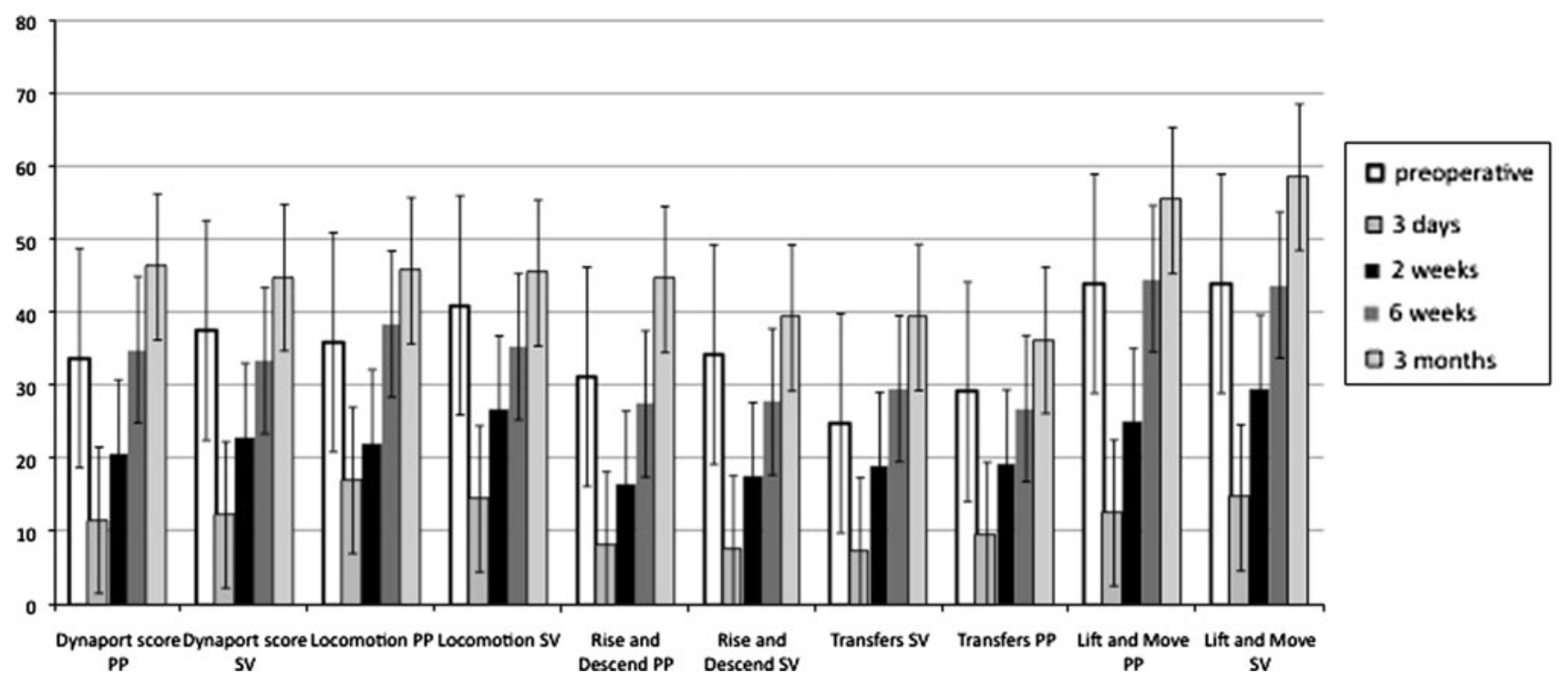

Fig. 4 The Dynaport ${ }^{\circledR}$ knee test (mean $\pm \mathrm{SD}$ ) and subscores in time $P P$ parapatellar, $S V$ subvastus

Fig. 5 WOMAC score (mean $\pm \mathrm{SD}$ ) in time

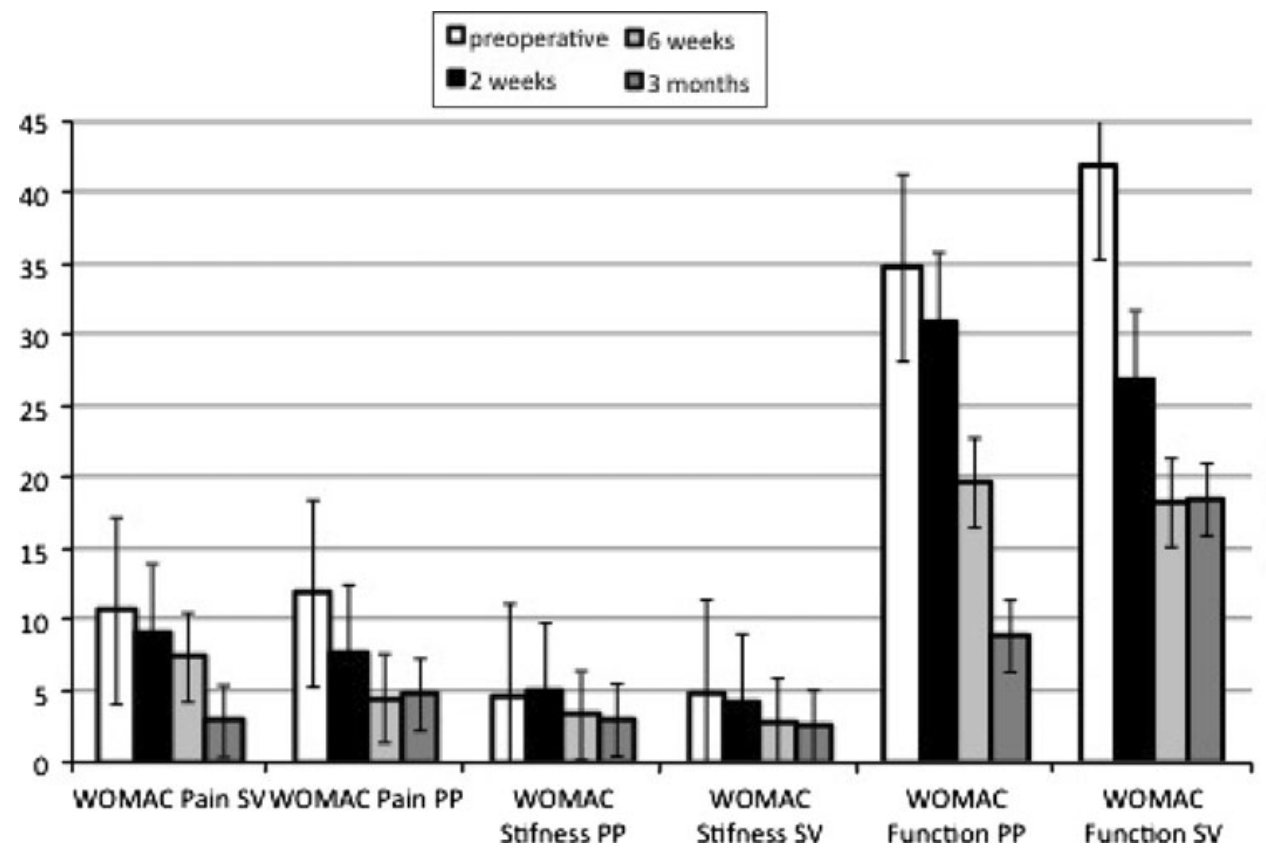

of neurovascular bundles between the oblique muscle bundles could be observed. The main branch originates through a double sheath of the deep fascia and runs until the distal end of the compartment (Fig. 6). The most distal neurovascular bundle in the left specimen appeared at only a few millimeters from the distal border of the vastus medialis compartment (Fig. 1). More proximally, further nerve vessel strands from 1.5 to $17 \mathrm{~cm}$ from the patellar base could be observed (Fig. 1).

Two aponeurotic plates emerged, one at the distal (Fig. 1) and one at the proximal side of the vastus medialis compartment. The distal aponeurosis was attached to the craniomedial and cranial side of the patella and the connective tissue at the medial side of the knee. A large aponeurotic plate consisting of dense connective tissue was found to lie parallel oriented with the fascia of the vastus medialis muscle and with the medial capsule of the knee (Fig. 6). This plate has to be severed to open the knee joint.

Proximally, the orientation of the muscle fibers changed to more vertically. Exploration of the transition between the oblique and more vertically oriented muscle fibers revealed only branches macroscopically claimed as neurovascular bundles, while dense connective tissue was less present. No dense connective tissue sheath was present 
Fig. 6 Black arrow neurovascular bundle between VMO and VMR

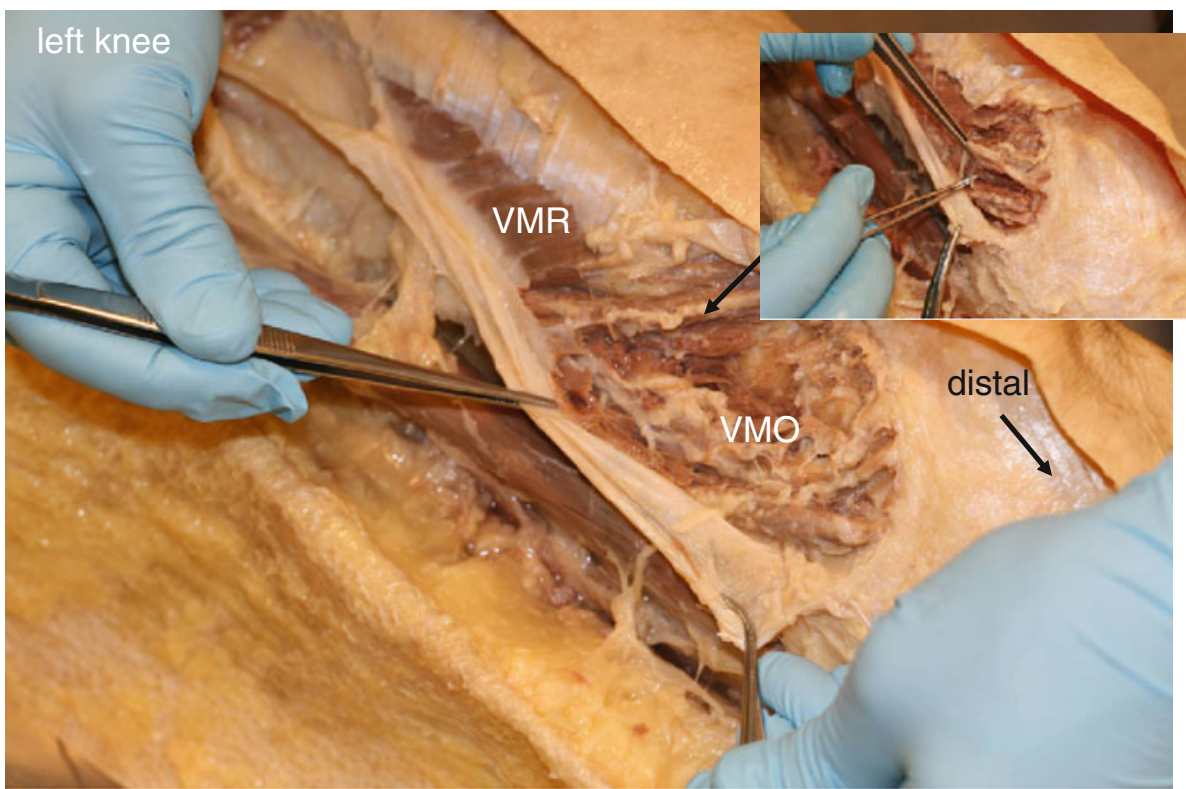

defining an exact border between a vastus medialis obliquus (VMO) and vastus medialis rectus (VMR), as described by others [10, 34] (Fig. 6).

In one specimen, the VMO and VMR separating entity containing claimed neurovascular bundles was prepared for histology and neurovascular structures embedded in loose connective tissue could indeed be identified (Fig. 7a-c).

\section{Discussion}

The most important finding in the present study was that only an early extension lag and WOMAC functioning was in favor of the subvastus group. We deliberately conducted a short-term clinical trial to focus on early recovery, as this is deemed to be faster [16], and both surgical procedures are considered to result in equal long-term outcome $[6,20$, $39,41]$. This is the first paper to combine the diseasespecific Western Ontario and McMaster Universities Index for Osteoarthritis (WOMAC) [4], Knee Society Score (KSS), and a objective performance-based tool (Dynaport ${ }^{\circledR}$ knee test), as well as pain-related score (VAS, PDI).

Current literature reports equal scores in terms of pain postoperative, blood loss, and need for substitution [39]. There is substantial pain relief compared with preoperative employing both approaches, but no significant difference was found.

The proportion that could mobilize the first day postoperatively and manual flexion measurements at the third day postoperative were not significantly different. Here, Weinrauch et al. [40] and Weinhardt et al. [39] found better results for the subvastus approach compared with the parapatellar approach.
Parent and Moffet [30] have demonstrated the usefulness of a gait test in early recovery. The Dynaport ${ }^{\circledR}$ knee test is rather sensitive in detecting small differences as demonstrated before [15, 37], and it can be concluded that in this study, patients operated on using a subvastus approach are not functionally superior.

Kreibich et al. [17] and Parent et al. [30] studied the responsiveness of various parameters in relation to outcome after knee replacement independently and considered WOMAC (functioning) most responsive especially in early recovery phase. The WOMAC functioning score in this study showed significant functional advantages and showed a significant steeper recovery after surgery, but this finding was reversed between 6 weeks and 3 months.

Quadriceps strength as measured by lag deficiency [40] occurred significantly less frequent in the subvastus approach at the third day. This was confirmed by Cila et al. [7]. They even found better results for the subvatus group within the first 3 months using mechanical quadriceps strength testing, but none beyond that time point.

In relation to quadriceps functioning, in the report of Matsueda et al. [20], there has been great focus on the patellofemoral joint [20]. Our patella tilt measurements showed no significant difference. Dynamic tests that challenge the patellofemoral function are reflected in the rise and descend subscore of the Dynaport ${ }^{\circledR}$ knee test. In a previous paper, we found this subscore discriminating in patellofemoral functioning [37]. However, the rise and descend subscore results also revealed no difference. It is uncertain how Matsueda et al. [20] and Ozkoc et al. [28] would correlate patellar tilting to clinical outcome.

Matsueda et al. [20] also report that fewer lateral retinacular releases have been performed in the subvastus 
Fig. 7 Histology of vastus medialis with identification of nerve strands $(H \& E$ hematoxylin eosin staining)
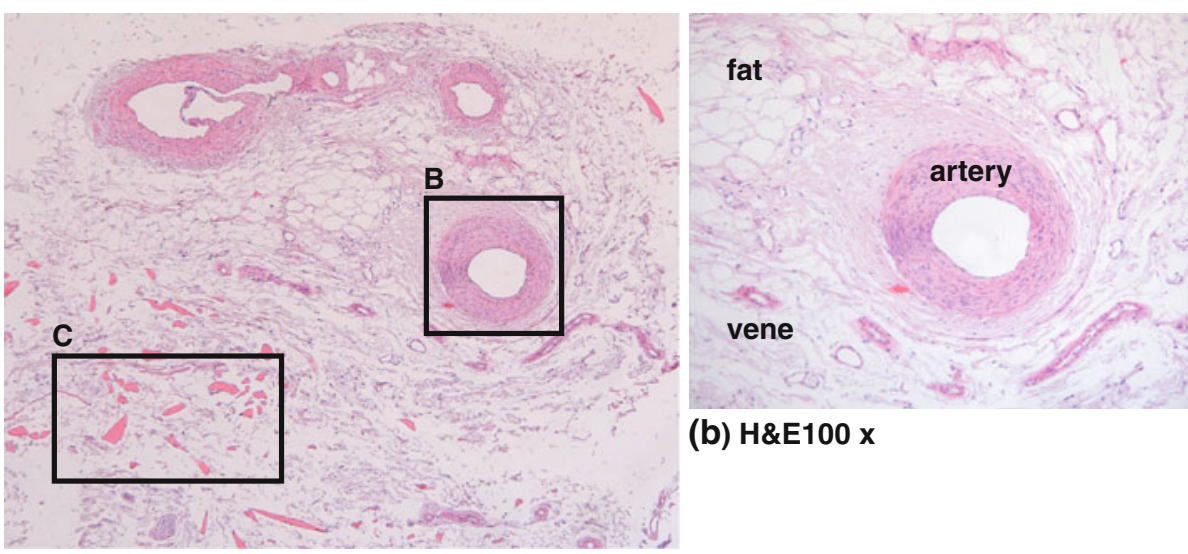

(b) H\&E100 $x$

(a) H\&E $45 x$

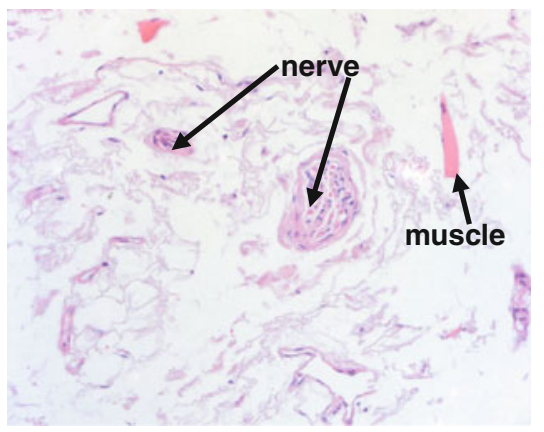

(c) H\&E $200 x$

group, but this should be a retinacular release, a consequence of imbalance in the patello-femoral joint, mainly due to incorrect rotation of the femoral component. Performing a lateral release may jeopardize the vascularity of the patella. In the dissection study (Fig. 2), the medial part of this extraosseous ring was found to be located in the layered medial patellar retinaculum. These structures are severed in either approach.

The vastus medialis obliquus (VMO) has been described as a separate entity of the vastus medialis muscle and held responsible for early quadriceps strength $[12,19,29$, 34]. However, employing a blunt dissection technique, a VMO structure was not encountered as a separate entity. This is an oblique or rather a more acute orientation of layered muscle fibers of the vastus medialis muscle. It is not separated by dense connective tissue resulting in a separate muscle unit. This has been supported by Hubbard et al. [12]. Only neurovascular structures were found at the level that is considered to be the anatomical border of the VMO.

The vascularisation and innervation of the distal vastus medialis located at immediate distal border of the vastus medialis fascia are at risk during the subvastus approach. Next to pain and joint effusion, this denervation could lead to loss of function, which was also speculated by Kelly et al. [14]. Loss of quadriceps muscle strength seems rather a neurological deficit and failure of voluntary muscle activation than pain or savage of the tendon itself $[24,25]$.

The anterior and medial vastus medialis attachment to dense connective tissue layers of patellar insertion is preserved during subvastus approach. However, the posteromedial origo is severed. Here, a substantial part of the quadriceps attachment, considered as a major component in patellar stability, tracking and extensor mechanism [32], has to be released in order to perform the arthrotomy.

There are a few limitations in this study. The relatively small sample size chosen based on the power analysis for the Dynaport ${ }^{\circledR}$ knee test might result in type II error considering other parameters. VAS measurements near significances must be interpreted with caution. Preoperatively, the group already differs almost one point, and therefore postoperative significances may be caused by existing differences. Furthermore, this study is not a single surgeon series. As there are no major differences, we considered it to be of minor influence.

Next to generic and disease-specific scores, the use of objective or performance-based instruments in studies on functional outcome is warranted. Pain is likely to influence the difference between self-reported questionnaires and objective tests. 


\section{Conclusion}

In this study, no difference was found between the parapatellar approach and subvastus approach in terms of pain reduction and restoration of function, and both have anatomical disadvantages.

Acknowledgments We thank Maarten Werkman, Carola Munch, Tom Vanderhenst, and Ghislain Geurts for assistance.

Conflict of interest No benefits were received to initiate this study or will we accepted based on outcome.

Open Access This article is distributed under the terms of the Creative Commons Attribution Noncommercial License which permits any noncommercial use, distribution, and reproduction in any medium, provided the original author(s) and source are credited.

\section{References}

1. Argenson JN, Scuderi GR, Komistek RD, Scott WN, Kelly MA, Aubaniac JM (2005) In vivo kinematic evaluation and design considerations related to high flexion in total knee arthroplasty. J Biomech 38:277-284

2. Bach CM, Nogler M, Steingruber IE, Ogon M, Wimmer C, Gobel G, Krismer M (2002) Scoring systems in total knee arthroplasty. Clin Orthop Relat Res 399:184-196

3. Barink M, Van de Groes S, Verdonschot N, De Waal Malefijt M (2006) The difference in trochlear orientation between the natural knee and current prosthetic knee designs; towards a truly physiological prosthetic groove orientation. J Biomech 39:1708-1715

4. Bellamy N, Buchanan WW, Goldsmith CH, Campbell J, Stitt LW (1988) Validation study of WOMAC: a health status instrument for measuring clinically important patient relevant outcomes to antirheumatic drug therapy in patients with osteoarthritis of the hip or knee. J Rheumatol 15:1833-1840

5. Berth A, Urbach D, Neumann W, Awiszus F (2007) Strength and voluntary activation of quadriceps femoris muscle in total knee arthroplasty with midvastus and subvastus approaches. J Arthroplasty $22: 83-88$

6. Chen AF, Alan RK, Redziniak DE, Tria AJ Jr (2006) Quadriceps sparing total knee replacement. The initial experience with results at two to four years. J Bone Joint Surg Br 88:1448-1453

7. Cila E, Guzel V, Ozalay M, Tan J, Simsek SA, Kanatli U, Ozturk A (2002) Subvastus versus medial parapatellar approach in total knee arthroplasty. Arch Orthop Trauma Surg 122:65-68

8. Davies AP (2002) Rating systems for total knee replacement. Knee 9:261-266

9. Franklin PD, Li W, Ayers DC (2008) The chitranjan ranawat award: functional outcome after total knee replacement varies with patient attributes. Clin Orthop Relat Res 466:2597-2604

10. Holt G, Nunn T, Allen RA, Forrester AW, Gregori A (2008) Variation of the vastus medialis obliquus insertion and its relevance to minimally invasive total knee arthroplasty. J Arthroplasty 23:600-604

11. Huang HT, Su JY, Chang JK, Chen CH, Wang GJ (2007) The early clinical outcome of minimally invasive quadriceps-sparing total knee arthroplasty: report of a 2-year follow-up. J Arthroplasty $22: 1007-1012$
12. Hubbard JK, Sampson HW, Elledge JR (1997) Prevalence and morphology of the vastus medialis oblique muscle in human cadavers. Anat Rec 249:135-142

13. Insall JN, Dorr LD, Scott RD, Scott WN (1989) Rationale of the knee society clinical rating system. Clin Orthop Relat Res 248:13-14

14. Kelly MJ, Rumi MN, Kothari M, Parentis MA, Bailey KJ, Parrish WM, Pellegrini VD Jr (2006) Comparison of the vastus-splitting and median parapatellar approaches for primary total knee arthroplasty: a prospective, randomized study. J Bone Joint Surg Am 88:715-720

15. Kleijn LL, van Hemert WL, Meijers WG, Kester AD, Lisowski L, Grimm B, Heyligers IC (2007) Functional improvement after unicompartmental knee replacement: a follow-up study with a performance based knee test. Knee Surg Sports Traumatol Arthrosc 10:1187-1193

16. Kort N (2007) Unicompartmental knee arthroplasty. Thesis. University of Groningen. 76-87

17. Kreibich DN, Vaz M, Bourne RB, Rorabeck CH, Kim P, Hardie R, Kramer J, Kirkley A (1996) What is the best way of assessing outcome after total knee replacement? Clin Orthop Relat Res 331:221-225

18. Lavernia CJ, D' Apuzzo MR, Hernandez VH, Lee DJ, Rossi MD (2006) Postdischarge costs in arthroplasty surgery. J Arthroplasty 21:144-150

19. Lefebvre R, Leroux A, Poumarat G, Galtier B, Guillot M, Vanneuville G, Boucher JP (2006) Vastus medialis: anatomical and functional considerations and implications based upon human and cadaveric studies. J Manipulative Physiol Ther 29:139-144

20. Matsueda M, Gustilo RB (2000) Subvastus and medial parapatellar approaches in total knee arthroplasty. Clin Orthop Relat Res 371:161-168

21. Maxwell S, Delaney H (2003) Designing experiments and analyzing data: a model comparison perspective, 2nd edn. Lawrence Erlbaum, UK

22. Miner AL, Lingard EA, Wright EA, Sledge CB, Katz JN (2003) Knee range of motion after total knee arthroplasty: how important is this as an outcome measure? J Arthroplasty 18:286-294

23. Mizner RL, Petterson SC, Snyder-Mackler L (2005) Quadriceps strength and the time course of functional recovery after total knee arthroplasty. J Orthop Sports Phys Ther 35:424-436

24. Mizner RL, Petterson SC, Stevens JE, Vandenborne K, SnyderMackler L (2005) Early quadriceps strength loss after total knee arthroplasty. The contributions of muscle atrophy and failure of voluntary muscle activation. J Bone Joint Surg Am 87:1047-1053

25. Mizner RL, Stevens JE, Snyder-Mackler L (2003) Voluntary activation and decreased force production of the quadriceps femoris muscle after total knee arthroplasty. Phys Ther 83:359-365

26. Mokkink LB, Terwee CB, van der Slikke RM, van Lummel RC, Benink RJ, Bouter LM, de Vet HC (2005) Reproducibility and validity of the Dynaport Kneetest. Arthritis Rheum 53:357-363

27. Mokkink LB, Terwee CB, van Lummel RC, de Witte SJ, Wetzels L, Bouter LM, de Vet HC (2005) Construct validity of the Dynaport Kneetest: a comparison with observations of physical therapists. Osteoarthr Cartil 13:738-743

28. Ozkoc G, Hersekli MA, Akpinar S, Ozalay M, Uysal M, Cesur N, Tandogan RN (2005) Time dependent changes in patellar tracking with medial parapatellar and midvastus approaches. Knee Surg Sports Traumatol Arthrosc 13:654-657

29. Panagiotopoulos E, Strzelczyk P, Herrmann M, Scuderi G (2006) Cadaveric study on static medial patellar stabilizers: the dynamizing role of the vastus medialis obliquus on medial patellofemoral ligament. Knee Surg Sports Traumatol Arthrosc 14:7-12 
30. Parent E, Moffet H (2002) Comparative responsiveness of locomotor tests and questionnaires used to follow early recovery after total knee arthroplasty. Arch Phys Med Rehabil 83:70-80

31. Ryd L, Karrholm J, Ahlvin P (1997) Knee scoring systems in gonarthrosis. Evaluation of interobserver variability and the envelope of bias. Score assessment Group. Acta Orthop Scand 68:41-45

32. Sakai N, Luo ZP, Rand JA, An KN (2000) The influence of weakness in the vastus medialis oblique muscle on the patellofemoral joint: an in vitro biomechanical study. Clin Biomech (Bristol, Avon) 15:335-339

33. Tait RC, Pollard CA, Margolis RB, Duckro PN, Krause SJ (1987) The pain disability index: psychometric and validity data. Arch Phys Med Rehabil 68:438-441

34. Taskiran E, Dinedurga Z, Yagiz A, Uludag B, Ertekin C, Lok V (1998) Effect of the vastus medialis obliquus on the patellofemoral joint. Knee Surg Sports Traumatol Arthrosc 6:173-180

35. van den Akker-Scheek I (2007) Recovery after short-stay total hip and knee arthroplasty. Evaluation of a support program and outcome determination. Thesis University of Groningen. $111-128$

36. van den Dikkenberg N, Meijer OG, van der Slikke RM, van Lummel RC, van Dieen JH, Pijls B, Benink RJ, Wuisman PI
(2002) Measuring functional abilities of patients with knee problems: rationale and construction of the Dynaport knee test. Knee Surg Sports Traumatol Arthrosc 10:204-212

37. van Hemert WL, Senden R, Grimm B, Kester AD, van der Linde MJ, Heyligers IC (2008) Patella retention versus replacement in total knee arthroplasty; functional and clinimetric aspects. Arch Orthop Trauma Surg 2:259-265

38. van Mameren H, Lataster A, Rensema H, Drukker J (1985) The use of modern imaging techniques (CT-scanning and NMR) in the study of the locomotor apparatus. Acta Morphol Neerl Scand 23:247-257

39. Weinhardt C, Barisic M, Bergmann EG, Heller KD (2004) Early results of subvastus versus medial parapatellar approach in primary total knee arthroplasty. Arch Orthop Trauma Surg 124:401-403

40. Weinrauch P, Myers N, Wilkinson M, Dodsworth J, Fitzpatrick P, Whitehouse S (2006) Comparison of early postoperative rehabilitation outcome following total knee arthroplasty using different surgical approaches and instrumentation. J Orthop Surg (Hong Kong) 14:47-52

41. White RE Jr, Allman JK, Trauger JA, Dales BH (1999) Clinical comparison of the midvastus and medial parapatellar surgical approaches. Clin Orthop Relat Res 376:117-122 